\title{
Full-vector geomagnetic field records from the East Eifel, Germany
}

\author{
Marilyn W.L. Monster ${ }^{\mathrm{a}, \mathrm{b}}$, Jaap Langemeijer ${ }^{\mathrm{a}}$, Laura R. Wiarda ${ }^{\mathrm{a}}$, Mark J. Dekkers ${ }^{\mathrm{a}}$, Andy J. Biggin ${ }^{\mathrm{c}}$, \\ Elliot A. Hurst ${ }^{\mathrm{c}}$, Lennart V. de Groot ${ }^{\mathrm{a}, *}$ \\ a Paleomagnetic Laboratory Fort Hoofddijk, Department of Earth Sciences, Utrecht University, Budapestlaan 17, 3584 CD Utrecht, The Netherlands \\ ${ }^{\mathrm{b}}$ Geology and Geochemistry Cluster, Faculty of Earth and Life Sciences, Vrije Universiteit Amsterdam, De Boelelaan 1085, 1081 HV Amsterdam, The Netherlands \\ ${ }^{c}$ Geomagnetism Laboratory, Oliver Lodge Labs, School of Environmental Sciences, University of Liverpool, Oxford Street, Liverpool L69 7ZE, UK
}

\section{A R T I C L E I N F O}

\section{Keywords:}

Palaeointensity

East Eifel volcanic field

Geomagnetic field

Brunhes chron

\begin{abstract}
A B S T R A C T
To create meaningful models of the geomagnetic field, high-quality directional and intensity input data are needed. However, while it is fairly straightforward to obtain directional data, intensity data are much scarcer, especially for periods before the Holocene. Here, we present data from twelve flows (age range $\sim 200$ to $\sim 470 \mathrm{ka}$ ) in the East Eifel volcanic field (Germany). These sites had been previously studied and are resampled to further test the recently proposed multi-method palaeointensity approach. Samples are first subjected to classic palaeomagnetic and rock magnetic analyses to optimise the subsequent palaeointensity experiments. Four different palaeointensity methods - IZZI-Thellier, the multispecimen method, calibrated pseudo-Thellier, and microwave-Thellier - are being used in the present study. The latter should be considered as supportive because only one or two specimens per site could be processed. Palaeointensities obtained for ten sites pass our selection criteria: two sites are successful with a single approach, four sites with two approaches, three more sites work with three approaches, and one site with all four approaches. Site-averaged intensity values typically range between 30 and $35 \mu \mathrm{T}$. No typically low palaeointensity values are found, in line with paleodirectional results which are compatible with regular palaeosecular variation of the Earth's magnetic field. Results from different methods are remarkably consistent and generally agree well with the values previously reported. They appear to be below the average for the Brunhes chron; there are no indications for relatively higher palaeointensities for units younger than $300 \mathrm{ka}$. However, our young sites could be close in age, and therefore may not represent the average intensity of the paleofield. Three of our sites are even considered coeval; encouragingly, these do yield the same palaeointensity within uncertainty bounds.
\end{abstract}

\section{Introduction}

Current geomagnetic field models (e.g. Knudsen et al., 2008; Ziegler et al., 2011) are hampered by a lack of reliable palaeointensity data. It is usually not straightforward to assess the reliability of the outcome of a palaeointensity experiment; their success rates remain low despite recent methodological advances pertaining to the classic Thellier-style palaeointensity protocol (Thellier and Thellier, 1959; Coe, 1967) such as the IZZI protocol (Tauxe and Staudigel, 2004; Yu et al., 2004). In addition, alternative palaeointensity methods that rely on different premises have been established like the microwave method (Hill and Shaw, 1999) or the multispecimen protocol (Dekkers and Böhnel, 2006; Fabian and Leonhardt, 2010). To increase the reliability of palaeointensity results several checks are built-in the measurement sequence (e.g. Coe, 1967; Riisager and Riisager, 2001) and a set of selection criteria can be applied to weed out doubtful results (e.g.
Paterson et al., 2014). Most recently, a multi-method approach has been proposed to increase the success rate of (tedious) palaeointensity experiments (de Groot et al., 2013; Monster et al., 2015a). This approach at the same time provides an additional consistency check: if methods that are based on different principles yield a similar result, the obtained palaeointensity is much more likely to be correct. This study further explores this approach: we revisited twelve sites in the East Eifel volcanic field (Germany) for which high-quality Thellier-style palaeointensity results were reported by Schnepp (1996) following the Coe version (Coe, 1967) of the Thellier method. Here, we base our interpretation on four different palaeointensity methods. Two methods involve heating of the samples: the IZZI-Thellier protocol (Yu et al., 2004) and the multispecimen protocol (Dekkers and Böhnel, 2006; Fabian and Leonhardt, 2010). The third method, the microwave method, adopts microwave excitation rather than thermal excitation of the magnetic grains (Hill and Shaw, 1999) but is in its execution very

\footnotetext{
* Corresponding author.

E-mail address: l.v.degroot@uu.nl (L.V.d. Groot).
} 


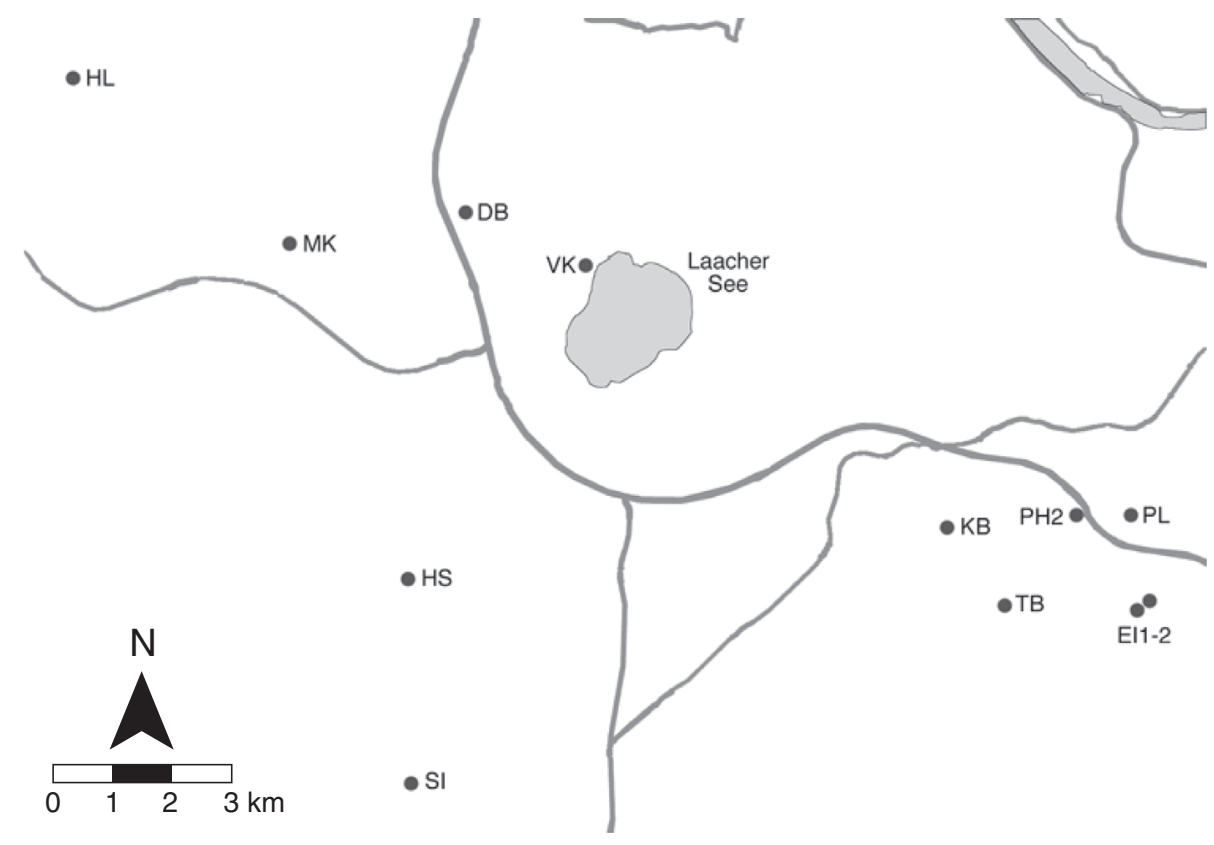

Fig. 1. Schematic location map of the fieldwork area. The main roads, as well as the Laacher See and the Rhine are indicated. Image adapted from Google Maps. GPS locations are provided in Table 1 .

similar to the classic Thellier-style experiments. The fourth method is a non-heating method, the calibrated pseudo-Thellier protocol (Tauxe et al., 1995; de Groot et al., 2013) which relies on an experimentally derived calibration (de Groot et al., 2013). We only sampled radiometrically dated sites with either the K/Ar or the ${ }^{39} \mathrm{Ar} /{ }^{40} \mathrm{Ar}$ method (Schmincke and Mertes, 1979; Fuhrmann and Lippolt,1985, 1986; van den Bogaard et al., 1989). The East Eifel volcanic field is Quaternary in age; ages of the sampled units range between $\sim 200 \mathrm{ka}$ and $\sim 470 \mathrm{ka}$.

\section{Geological setting and sampling}

The Quaternary Eifel volcanic field is subdivided into the West Eifel and East Eifel volcanic fields (Schmincke, 2007). The Hoch Eifel volcanic field is of mainly Eocene age. The West Eifel volcanic field is located close to the border with Belgium and Luxemburg while the East Eifel volcanic field stretches a little west of Koblenz; the Laacher See is more or less in its center (Fig. 1). Volcanic activity begun in the West Eifel field at $\sim 700 \mathrm{ka}$ as a response to accelerated uplift of the Rhenish shield due to mantle plume activity (Ritter et al., 2001). Magmas intruded in very low-grade metamorphic graywackes, sandstones and slates of Devonian age, metamorphosed during the Variscan orogeny and uplifted since Mesozoic times with an accelerated pace since $800 \mathrm{ka}$ (Meyer, 1986). The volcanic rocks are potassium-rich silica-undersaturated igneous rocks; they include basanites, leucitites, nephelinites, tephrites, and phonolites. The latter were shown to be largely unsuited for palaeointensity determination purposes (Schnepp and Hradetsky, 1994; Schnepp, 1994, 1995, 1996). Volcanoes are dominantly scoria cones and maars, typical of intraplate volcanism. Half of them erupted lava flows (Schmincke, 2007). Volcanic activity in the East Eifel volcanic field started at $\sim 460 \mathrm{ka}$. Older rocks in both the West and East Eifel volcanic fields are dominated by phonolitic rocks. Younger volcanic rocks are highly evolved phonolites (Wehr crater complex, $\sim 215 \mathrm{ka}$ ), and basanitic and tephritic scoria cones which mostly erupted during 215-190 ka. They are potassium-rich in contrast to the young rocks of the West Eifel field that are more sodium-rich (Schmincke, 2007). The lavas of East Eifel volcanic field erupted primarily in the downfaulted Neuwied basin, which is part of the Rhine Rift. The East Eifel volcanic field is more voluminous than the West Eifel field. The volcanism in the Eifel is presently considered dormant but not extinct (Schmincke, 2007).

The East Eifel volcanic field is a volcanic area of about $400 \mathrm{~km}^{2}$ located west of Koblenz, Germany. It consists of $\sim 100$ volcanoes, with $\sim 80 \%$ scoria cones. Lava flows, tuff rings are comparatively rare; some phonolitic complexes occur (Schnepp, 1996). It is subdivided into two main phases of volcanism: the poorly exposed older eruptive centres (c. $400 \mathrm{ka}$ ) west of the Laacher See and the younger centres (c. $200 \mathrm{ka}$ ) east of the Laacher See. The volcanic activity is argued to be episodic with eruptive intervals intertwined with longer periods of no eruptive activity (Schmincke, 2007). In this study, only lava flows were sampled, with the exception of Hochstein (HS), which was a scoria cone.

To further test the multi-method palaeointensity approach (de Groot et al., 2013; Monster et al., 2015a), we revisited twelve sites from Schnepp (1996) that had previously been dated by Schmincke and Mertes (1979), Fuhrmann and Lippolt $(1985,1986)$ and van den Bogaard et al. (1989). The sites are given in Table 1 ordered from young to old. All younger rocks from the eastern portion of the field are basanites (TB, EI1, EI2, PL, PH2, KB, DB, VK) while older rocks from the western portion include leucitites (SI, MK) and nephelinites (HS, HL). HL belongs to oldest Kempenich center while the other old sites (HS, SI, MK) belong to the Riedener volcanic complex. DB and VK belong the eastern portion of the East Eifel volcanic field and the youngest rocks (TB, EI1, EI2, PL, PH2, KB) to southeastern subfield (Schmincke, 2007). At Korretsberg (KB; KB1 in Schnepp (1996)), Meirother Kopf (MK) and Plaidter Hummerich ( $\mathrm{PH} 2$ ) the precise original sampling locations were recovered. For the other sites, no existing drill holes could be traced, although we did sample the same eruption centres. Especially in quarries such as the Eiterköpfe (EI1-2), Plaidt (PL), Hochsimmer (SI) and Tönchesberg (TB) the original sampling locations often did not exist anymore or were inaccessible. The original sites EI1-2, for example, had been converted to a waste disposal site.

At each site, at least fifteen 1-in. diameter cores were drilled using a portable, petrol powered drill. At each site a number of samples were taken as close together as possible to ensure homogeneity of the magnetic properties among these samples and hence make a comparison between results from different paleointensity techniques meaningful; furthermore, a number of samples were taken spaced metres apart to improve the quality of the mean paleomagnetic direction obtained for each site. Samples were oriented with a magnetic compass and if possible also a sun compass (all sites except HS, MK and TB). For most sites, the sun compass correction was less than $5^{\circ}$; for sites Dachsbusch (DB), Hannebacher Ley (HL), Korretsberg (KB) and Plaidt (PL) the correction was somewhat larger, up to nearly $8^{\circ}$ for site KB. At locations 
Table 1

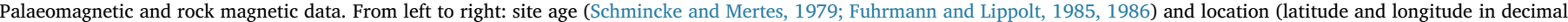

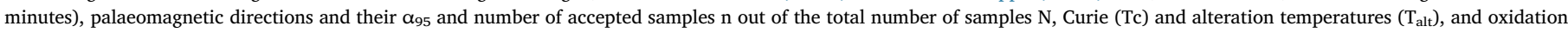
class according to Watkins and Haggerty (1968) for all twelve sites. Class I is pristine, VI is most oxidised.

\begin{tabular}{|c|c|c|c|c|c|c|c|c|c|c|c|}
\hline \multirow[t]{2}{*}{ Site } & \multirow[t]{2}{*}{ Age (ka) } & \multicolumn{2}{|l|}{ Location } & \multicolumn{5}{|c|}{ Palaeomagnetic directions } & \multicolumn{3}{|c|}{ Rock magnetic characteristics } \\
\hline & & Latitude $\left({ }^{\circ}\right)$ & Longitude $\left({ }^{\circ}\right)$ & $\operatorname{dec}\left({ }^{\circ}\right)$ & Inc. $\left({ }^{\circ}\right)$ & $\alpha 95\left(^{\circ}\right)$ & $\kappa$ & $\mathrm{n}(\mathrm{N})$ & $\mathrm{T}_{\mathrm{c}}\left({ }^{\circ} \mathrm{C}\right)$ & $\mathrm{T}_{\text {alt }}\left({ }^{\circ} \mathrm{C}\right)$ & Oxidation \\
\hline Tönchesberg (TB) & $202 \pm 13$ & 50.36844 & 7.36098 & 0.7 & 77.4 & 3.4 & 266.4 & $8(8)$ & 240,540 & $400-475$ & III-IV \\
\hline Eiterkopf 1 (EI1) & $213 \pm 40$ & 50.36789 & 7.39315 & 325.9 & 67.6 & 3.8 & 253.3 & $7(8)$ & 540 & $250-325$ & III-IV \\
\hline Eiterkopf 2 (EI2) & $213 \pm 40$ & 50.36919 & 7.39561 & 323.9 & 67.0 & 1.4 & 1567.0 & $8(8)$ & 570 & $250-325$ & III-IV \\
\hline Plaidt (PL) & $213 \pm 40$ & 50.38232 & 7.39104 & 331.9 & 71.3 & 2.1 & 697.0 & $8(8)$ & 540 & $250-325$ & III \\
\hline Plaidter Hummerich 2 (pH2) & $238 \pm 20$ & 50.38252 & 7.37817 & 346.3 & 49.3 & 4.5 & 180.9 & $7(8)$ & 160 & $250-325$ & II-III \\
\hline Korretsberg (KB) & $243 \pm 65$ & 50.38094 & 7.34711 & 0.6 & 70.6 & 3.1 & 380.2 & $7(8)$ & 570 & $400-475$ & III-IV \\
\hline Dachsbuch (DB) & $246 \pm 50$ & 50.42900 & 7.23158 & 10.0 & 64.2 & 3.6 & 282.1 & $7(8)$ & 500 & $325-400$ & I \\
\hline Veitskopf (VK) & $268 \pm 30$ & 50.42140 & 7.26041 & 5.1 & 45.2 & 3.8 & 253.3 & $7(8)$ & 570 & $325-400$ & III \\
\hline Hochstein (HS) & $350 \pm 50$ & 50.37296 & 7.21779 & 23.9 & -5.3 & 17.8 & 20.3 & $5(8)$ & 340 & 600 & I \\
\hline Hochsimmer (SI) & $410 \pm 30$ & 50.34157 & 7.21859 & 331.7 & 72.6 & 3.7 & 225.1 & $8(8)$ & 540 & $175-250$ & I-II \\
\hline Meirother Kopf (MK) & $420 \pm 30$ & 50.42427 & 7.18925 & 14.5 & 65.3 & 5.8 & 175.0 & $5(8)$ & 280,540 & $400-475$ & I-II \\
\hline Hannebacher Ley (HL) & $470 \pm 50$ & 50.44941 & 7.13726 & 33.5 & 71.4 & 6.9 & 65.4 & $8(8)$ & 540 & $400-475$ & I-II \\
\hline
\end{tabular}

Hochsimmer (SI) and Hochstein (HS) an additional, unoriented hand sample was taken due to drilling difficulties (SI) and the suspected likelihood of past lightning strikes at the only in situ outcrop (HS).

\section{Methods}

\subsection{Demagnetisation of the natural remanent magnetisation}

Samples were demagnetised with both thermal and alternating field (AF) demagnetisation. Three samples per site were heated in steps of $50{ }^{\circ} \mathrm{C}$ from 100 up to $500{ }^{\circ} \mathrm{C}$ and subsequently in steps of $25^{\circ} \mathrm{C}$ to $600^{\circ} \mathrm{C}$. Most specimens were measured on a 2G-DC SQUID magnetometer; the first demagnetisation levels of samples whose natural remanent magnetisation (NRM) exceeded $\sim 5 \mathrm{~A} / \mathrm{m}$ were measured on an AGICO JR-6 spinner magnetometer; when demagnetised to a sufficiently low magnetisation measurements were continued on the DCSQUID magnetometer. Five specimens per site were subjected to AF fields of $2.5,5,7.5,10,15,20,25,30,40,50,60,70,80,90$ and $100 \mathrm{mT}$, using a robotised 2G DC-SQUID magnetometer in a static 3axes demagnetisation set-up (Mullender et al., 2016); all demagnetisation data were analysed using RemaSoft (Chadima and Hrouda, 2006). Thermal and AF NRM decay curves were obtained by plotting the NRM intensity as a function of temperature and AF field strength, respectively. These data were normalized by the initial NRM.

\subsection{Rock magnetic analyses}

All sites were subjected to commonly adopted rock magnetic analyses. Curie and alteration temperatures (de Groot et al., 2012) were determined by measuring susceptibility as a function of temperature during several temperature cycles on an AGICO KLY-3S Kappabridge susceptometer with a CS3 furnace attachment (noise level $2 \cdot 10^{-7} \mathrm{SI}$, typical signal at least three orders of magnitude higher). Sample mass typically ranged between 0.5 and $1 \mathrm{~g}$ of crushed rock chips. During the first temperature cycle, the temperature was gradually increased to $175^{\circ} \mathrm{C}$ and then decreased to $125^{\circ} \mathrm{C}$. In subsequent cycles, the temperature was increased by $75^{\circ} \mathrm{C}$ and then decreased by $50{ }^{\circ} \mathrm{C}$. The alteration temperature is defined as the lowest temperature in the cycles at which irreversible behaviour occurs. Curie temperatures cannot be determined as precisely from susceptibility curves as from magnetisation-versus-temperature curves, but can be estimated from the inflection point or points of the decreasing branch of the susceptibility curve (Petrovsky and Kapicka, 2006).

Domain state estimates were determined from hysteresis loops and back-field remanence curves measured at room temperature on a MicroSense vibrating sample magnetometer (VSM). For each (sub)site one sample of 8-mm diameter and typical length of $6 \mathrm{~mm}$ was subjected to a maximum field of $1.5 \mathrm{~T}$ in the hysteresis loops (75 measurement points, spaced more closely near the origin) and $0.53 \mathrm{~T}$ in the back-field remanence curves. From these plots, the values of the saturation remanent magnetisation $M_{r s}$, the saturation magnetisation $M_{s}$, the coercive field $B_{c}$ and the coercivity of remanence $B_{c r}$ were determined. A slope correction was applied to the hysteresis loops to remove the paramagnetic contribution. The ratios $M_{r s} / M_{s}$ and $B_{c} / B_{c r}$ were plotted against each other in a Day plot (Day et al., 1977). From this plot, the domain state of the samples can be estimated.

To estimate the oxidation class, thin sections were studied using a JEOL JCM-6000 table-top scanning electron microscope (SEM) in backscatter mode using an acceleration voltage of $10 \mathrm{kV}$. Images were taken at magnifications of up to $4000 \times$. Sites were categorised in the oxidation classes described in Watkins and Haggerty (1968).

\subsection{Palaeointensity experiments}

To increase the success rate and to provide an additional consistency check, we used four different palaeointensity methods: the 'classic' Thellier-Thellier method (Thellier and Thellier, 1959) with the IZZI protocol (Tauxe and Staudigel, 2004; Yu et al., 2004), the domainstate-corrected multispecimen protocol (Dekkers and Böhnel, 2006; Fabian and Leonhardt, 2010), the calibrated pseudo-Thellier method (de Groot et al., 2013) and the microwave method (Hill and Shaw, 1999). As all four methods take a different approach to obtain an estimate of the absolute palaeofield, consistency between their results is a strong indication that the obtained palaeointensity is reliable (de Groot et al., 2013; Monster et al., 2015a).

The IZZI protocol was applied with partial thermoremanent magnetisation (pTRM) checks (Coe, 1967) and pTRM tail checks (Riisager and Riisager, 2001) to seven specimens per site. A laboratory field of $50 \mu \mathrm{T}$ was used with an angle of $0-90^{\circ}$ to the samples' NRM. Data were analysed using ThellierTool 4.0 (Leonhardt et al., 2004). The reliability of the results was assessed using the built-in ThellierTool A and B sets of selection criteria (Leonhardt et al., 2004) as modified by Paterson et al. (2014). The selection criteria for TTB are as follows (all statistics as defined by Paterson et al. (2014)): number of points (n) $\geq 5$; fraction (f) $\geq 0.35$; the ratio of the standard error of the slope to the absolute value of the slope $(\beta) \leq 0.15$; quality parameter $(q) \geq 0$; the maximum angular deviation of the anchored directional fits to the paleomagnetic vector $\left(M_{A} D_{a n c}\right) \leq 15$; the angular difference between the anchored and free-floating best-fit directions $(\alpha) \leq 15$; Maximum absolute difference produced by a pTRM check, normalized by the total TRM (Leonhardt et al., 2004) $(\delta \mathrm{CK}) \leq 9$; the alteration determined by the difference of the alteration corrected intensity estimate and the uncorrected estimate, normalized by the uncorrected estimate (Leonhardt et al., 2004) ( $\delta$ pal) $\leq 18$; the maximum absolute difference produced 
by a pTRM tail check, normalized by the NRM (Leonhardt et al., 2004) $(\delta T R) \leq 20$; the extent of a pTRM tail after correction for angular dependence (Leonhardt et al., 2004) $\left(\delta t^{*}\right) \leq 99$. For the TTA set most of the criteria are the same as for TTB, except for: $\beta \leq 0.10$; $\mathrm{q} \geq 5$; MA$\mathrm{D}_{\text {anc }} \leq 6 ; \delta \mathrm{CK} \leq 7 ; \delta \mathrm{pal} \leq 10 ; \delta \mathrm{TR} \leq 10 ; \delta \mathrm{t}^{*} \leq 9$. Finally, samples that passed these selection criteria but showed nonetheless sagging, indicative of multi-domain effects, were considered less reliable. IZZIThellier site averages were only considered to be acceptable if they are the mean of at least three independent samples for which the standard deviation divided by the average palaeointensity should not exceed 20\% (after Selkin and Tauxe, 2000).

In the multispecimen (MSP) protocol, all sites that did not reveal an overprint in their thermal and AF Zijderveld diagrams were first subjected to the so-called ARM test (de Groot et al., 2012; ARM stands for anhysteretic remanent magnetisation). The potential set temperatures were selected based on their susceptibility-versus-temperature plots (no alteration should occur) and their NRM thermal decay curves (decay is at least $15 \%$ at the ARM test temperature) similarly to the workflow in de Groot et al. (2013, 2015, 2016). Furthermore, temperatures below $200{ }^{\circ} \mathrm{C}$ were not selected to avoid low-temperature viscous overprints even further. No prior AF demagnetisation should be carried out prior to the ARM acquisition as this precludes a meaningful outcome of the ARM test (de Groot et al., 2012). The ARM gained is determined by subjecting half of the samples from the pristine and heated cores to an ARM acquisition in bias field of $40 \mu \mathrm{T}$, whereas the other half are subjected to single-axis AF demagnetisation in the same axis, equivalent to an ARM acquisition in $0 \mu \mathrm{T}$ bias field. If a core heated to the selected temperature gains the same amount of ARM as an unheated (pristine) core, it is very plausible that the MSP protocol method will yield the correct palaeointensity. Only the sites that passed the ARM test were subjected to the domain-state-corrected multispecimen protocol (MSPDSC) at the same temperature as the ARM test. We used four field levels $(15,30,45$ and $60 \mu \mathrm{T})$ and three specimens per field level. Data were analysed using MSP-Tool for MS Excel 2010 (Monster et al., 2015b) and its built-in reliability criteria. If the average alteration $\varepsilon_{\text {alt }}$ between the first and fourth heating step exceeded 3\% (de Groot et al., 2013) and/or if the intersection with the y-axis of the linear fit in the domain-statecorrected plot was not within error of its theoretically prescribed value of $(0,-1)$ (Fabian and Leonhardt, 2010), the result from the original method (MSP-DB; Dekkers and Böhnel, 2006) was preferred. Data points that were outside the bootstrapped confidence interval (Monster et al., 2015b) that was initially produced based on the results of all measured samples were rejected and the data were reinterpreted omitting these data points.

The calibrated pseudo-Thellier method (Tauxe et al., 1995; de Groot et al., 2013) was applied to five specimens per site. After AF demagnetisation (Section 3.1), these samples were subjected to an ARM acquisition at the same AF field steps (up to $100 \mathrm{mT}$ ), using a DC bias field of $40 \mu \mathrm{T}$. The NRM remaining after each AF step was plotted against the pARM gained after each step in a 'pseudo-Arai plot'. As a third step, the ARM was demagnetised using the same AF steps to test whether the ARM was carried by the same grains as the NRM. If that is the case, a plot of the NRM remaining against the ARM remaining should show a straight line. Results were analysed using a custom-made VBA Excel macro. The slope of the pseudo-Arai plot was converted to an absolute palaeointensity using the empirically derived calibration formula from de Groot et al. (2015). This formula is based on data from Hawaii (de Groot et al., 2013) and the Canary Islands (de Groot et al., 2015). It is valid for samples whose value of $B_{1 / 2 A R M}$, the AF field at which they have gained $50 \%$ of their maximum ARMs, is between 23 and $63 \mathrm{mT}$ (de Groot et al., 2013). Pseudo-Thellier site averages are only considered to be acceptable if they are the mean of at least three independent samples.

Finally, the microwave method (Hill and Shaw, 1999) was used. This method is similar to the classic Thellier-Thellier protocol, but instead of heating the samples, the samples are demagnetised using microwaves that directly excite the magnetic spin system. This should reduce the amount of heating experienced by the specimens and therefore the amount of alteration. The experiments were carried out at the University of Liverpool. We used microwave equivalent of the IZZI protocol (Yu et al., 2004) including pTRM checks (Coe, 1967), at a laboratory field of $30 \mu \mathrm{T}$. The specimen from site TB was measured using a field of $40 \mu \mathrm{T}$ and for site $\mathrm{DB}$, which was expected to yield a higher palaeointensity, a laboratory field of $60 \mu \mathrm{T}$ was used. Data were analysed using ThellierTool 4.0 (Leonhardt et al., 2004) and its built-in ThellierTool A and B selection criteria as modified by Paterson et al. (2014). Samples of 5-mm diameter and $\sim 5 \mathrm{~mm}$ length were used. Due to time constraints, only one or two specimens per site were processed. Because of the limited number of specimens per flow that could be processed the outcome should be considered as supportive of other palaeointensity determination approaches.

\section{Results}

\subsection{Palaeomagnetic directions}

Representative Zijderveld diagrams and thermal decay curves are shown in Fig. 2. All obtained mean palaeodirections are provided in Table 1. Examples for all twelve sites are in Appendix A. Most sites show univectorial behaviour in their Zijderveld diagrams, although four sites (DB, KB, MK and PH2) as well as some individual samples from HS, EI1, HL, SI and VK have small overprints that are removed after demagnetisation at $5-10 \mathrm{mT}$ or $100-150^{\circ} \mathrm{C}$. The obtained directions for sites DB, HL, MK, PH2 and TB are consistent with those of Schnepp (1996) (see equal area plots in Appendix B). Site HS is discarded from interpretation (cf. Fig. 6) as it shows a small overprint combined with a relatively high NRM intensity and a quick NRM decay during the first few AF demagnetisation steps. These characteristics, as well as its inconsistent palaeodirections $\left(\alpha_{95}=17.6^{\circ}\right)$, hint at a nearby lightning strike. Please note that palaeointensity experiments are carried out on the unoriented block sample (no in situ sampling possible).

Thermal decay curves are divided into two main groups. The first group demagnetises slowly until $\sim 400{ }^{\circ} \mathrm{C}$ and more quickly at higher temperatures, with sometimes two distinct phases (e.g. sites DB, EI1, EI2 and HS). The second, smaller, group demagnetises more quickly, retaining $50 \%$ or less of its initial NRM after demagnetisation at $300^{\circ} \mathrm{C}$. AF NRM decay curves are distinctly variable. Most sites retain less than $\sim 20 \%$ of their NRM after demagnetisation at $100 \mathrm{mT}$, but sites DB, EI1, TB and some samples from sites EI2 and MK lose $<40 \%$ of their initial NRM at that field level (Appendix A).

\subsection{Rock magnetic analyses}

Some representative susceptibility-versus-temperature plots are shown in Fig. 2; plots for all sites are provided in Appendix A. Curie and alteration temperatures are in Table 1 . Most sites show dominant high Curie temperatures of $>500{ }^{\circ} \mathrm{C}$. Sites MK, $\mathrm{PH} 2$ and TB, on the other hand, yield lower dominant Curie temperatures ranging $200-300^{\circ} \mathrm{C}$. These three sites also show another subordinate Curie temperature of $>500^{\circ} \mathrm{C}$. Site $\mathrm{HS}$ yields an intermediate Curie temperature of $\sim 350^{\circ} \mathrm{C}$. Alteration temperatures generally vary between 225 and $400^{\circ} \mathrm{C}$. Site HS is exceptional: it does not show visible thermochemical alteration until $600{ }^{\circ} \mathrm{C}$.

Although the $\mathrm{Mr} / \mathrm{Ms}$ and $\mathrm{Bcr} / \mathrm{Bc}$ ratios are bulk rock properties, hence averages of the behaviour of all magnetic fractions present in a sample, a Day plot (Fig. 3) may give a first-order indication of the magnetic grain size in the sample. Most sites plot in the pseudo-singledomain (PSD) range, generally slightly above the SD + MD mixing line (Dunlop, 2002). Site HL plots in the multidomain (MD) range. Site MK yields a very high $B_{c r} / B_{c}$ ratio (10.6) combined with a relatively high $M_{r} / M_{s}$ ratio (0.45) when measured on the VSM. Its hysteresis loop (Appendix A) shows two components, which makes its position on the 
Thermal decay curve
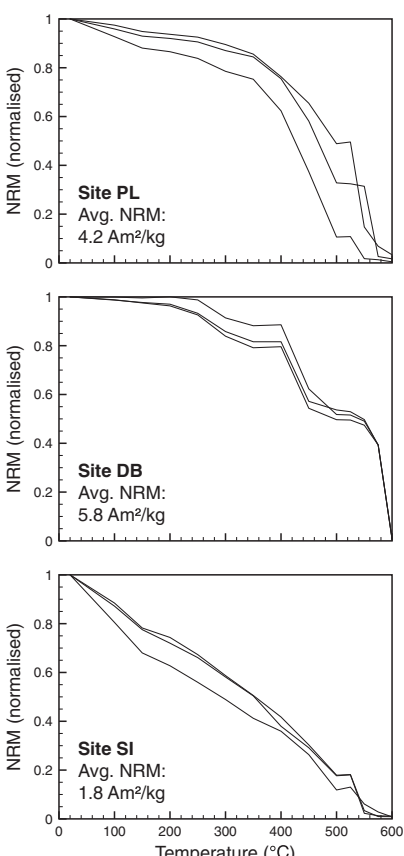

Zijderveld diagram (AF)
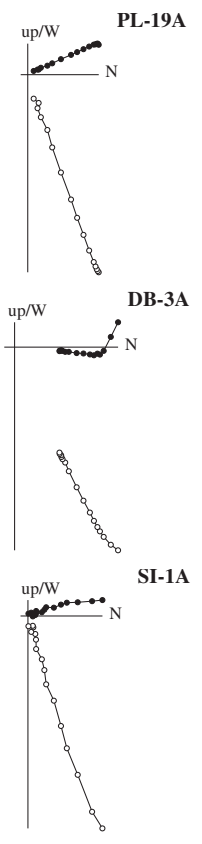

Hysteresis loop
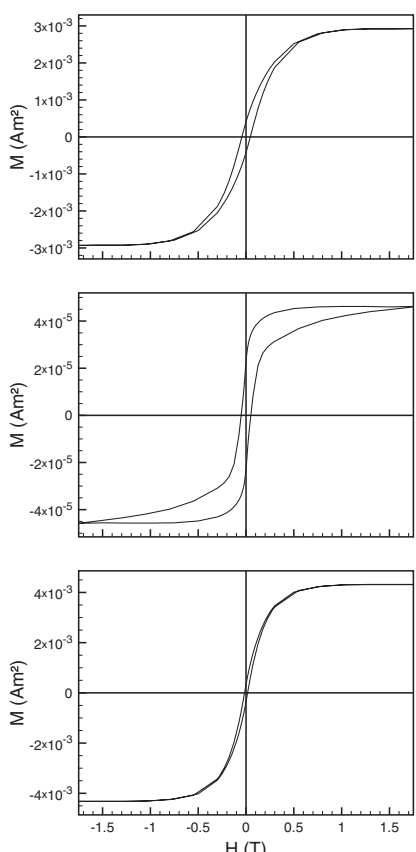

Susceptibility v. temperature
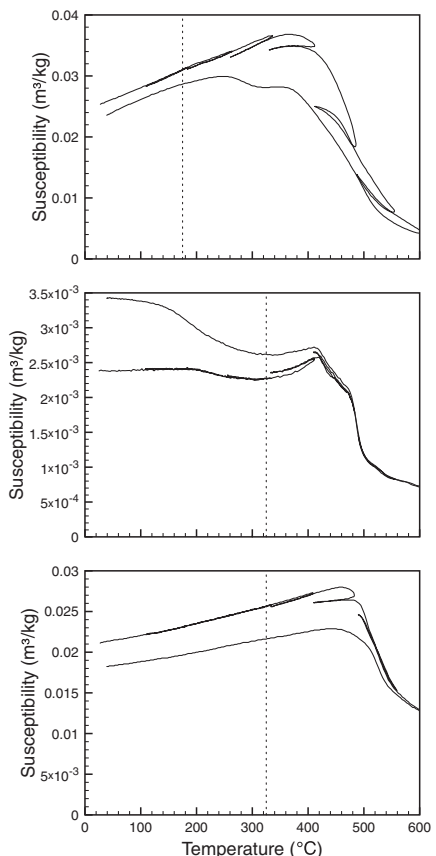

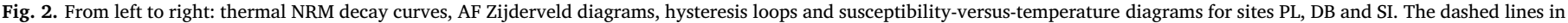
the susceptibility-versus-temperature diagrams indicate the alteration temperature.

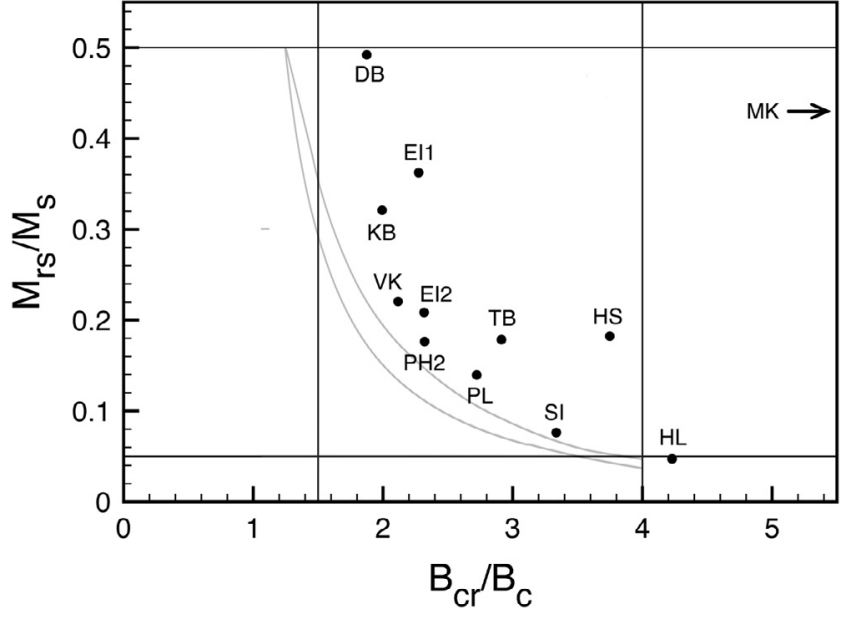

Fig. 3. Day plot showing the $M_{r} / M_{s}$ and $B_{c r} / B_{c}$ ratios of all twelve sites. The $S D+M D$ mixing curves (Dunlop, 2002) are shown in grey.
Day plot ambiguous.

The SEM images reveal varying oxidation states (Table 1, Fig. 4 and Appendix C). Generally speaking, the younger sites (200-300 ka) show higher oxidation levels than the older sites (>300 ka). Sites HS and DB are devoid of oxidation (class I). The abundant ilmenite lamellae observed for sites PL and VK place them in class III. Sites EI1-2, KB and TB show mottled lamellae and class in oxidation stage III-IV. The remaining sites show some signs of oxidation and are categorised in either class I-II (sites HL, MK, SI) or II-III (site PH2).

\subsection{Palaeointensity experiments}

The Thellier-Thellier method yields acceptable results for $45 \%$ of the individual samples, typically at least three specimens per site pass our selection criteria. Two representative plots are shown in Fig. 5; all plots of passing samples are in Appendix D. The complex mineralogy of lavas often leads to Arai diagrams that show scatter and are not ideal, our results are no exception, but seven out of twelve sites (DB, EI1-2, HS, KB, PL and TB) show linear fits, as well as one specimen from site VK. The paleomagnetic directions during the IZZI-Thellier experiments
Site HS: class I

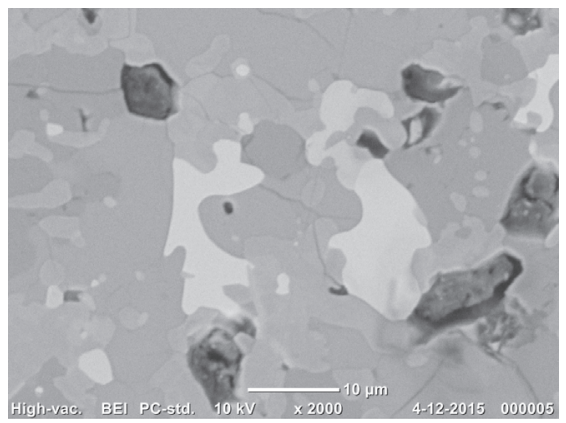

Site VK: class III

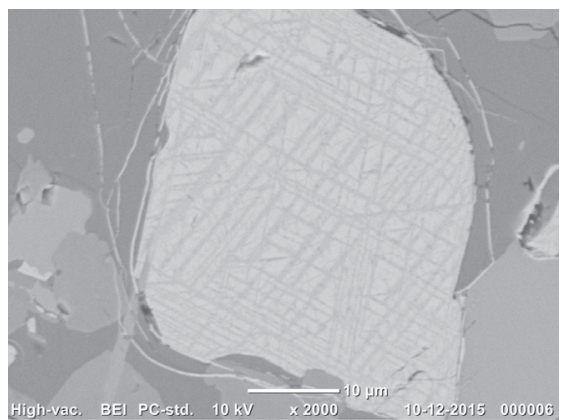

Site TB: class III-IV

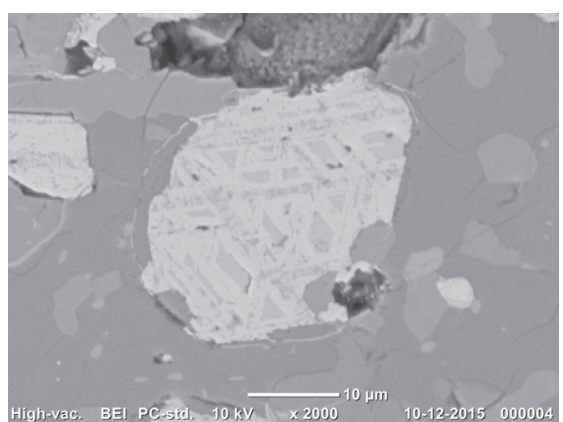

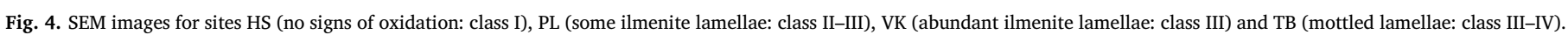



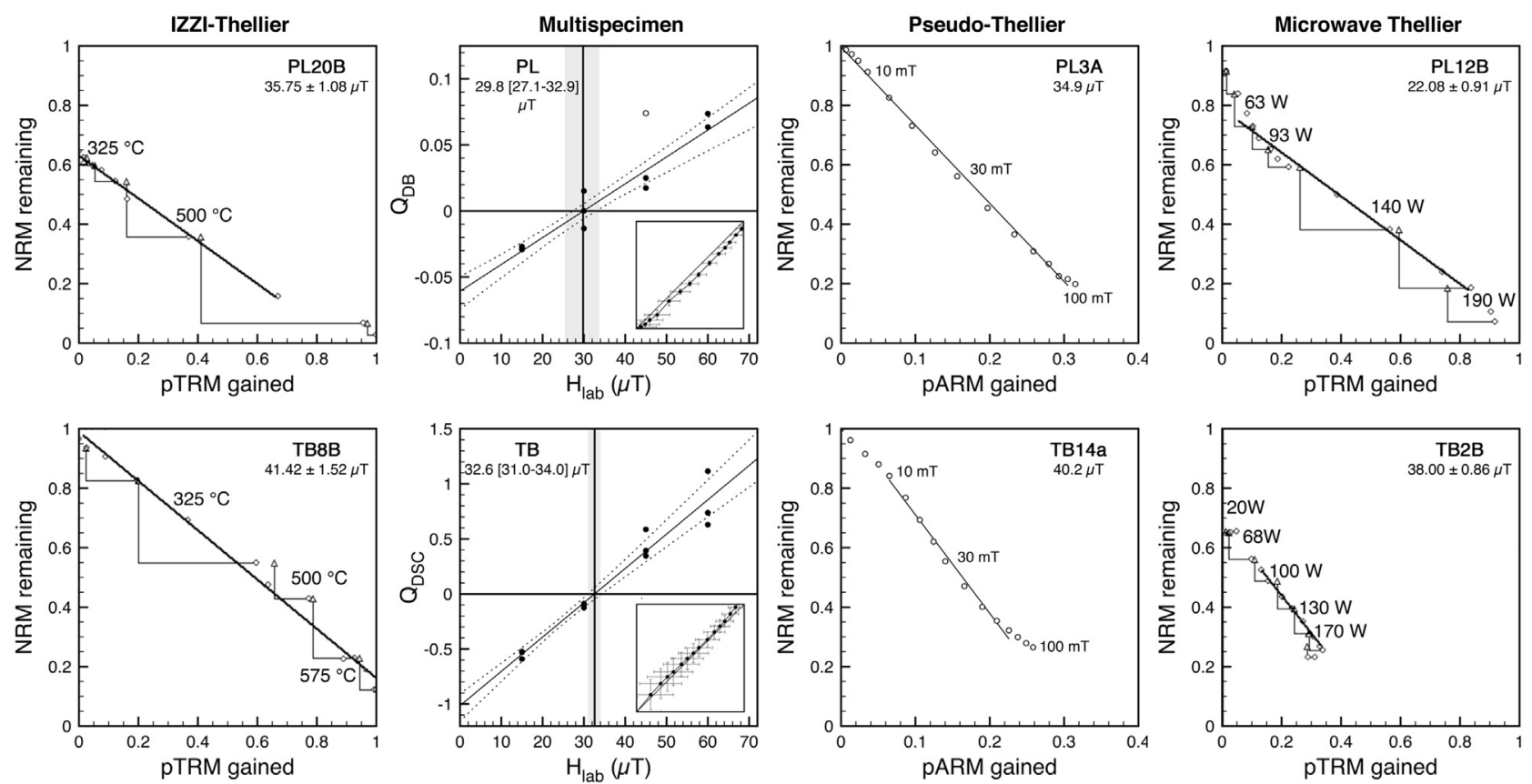

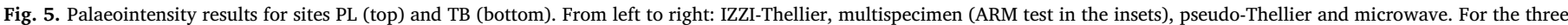
types of Arai plots, several temperature, field and power steps are indicated.

Table 2

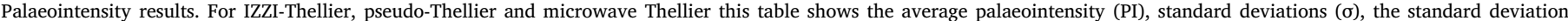

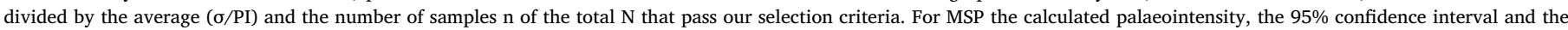

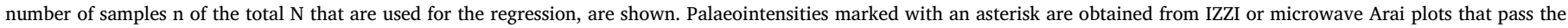
selection criteria but show sagging and are therefore considered less reliable. For site VK, only a few specimens show sagging. All palaeointensities are given in $\mu \mathrm{T}$.

\begin{tabular}{|c|c|c|c|c|c|c|c|c|c|c|c|c|c|c|c|c|c|}
\hline \multirow[t]{2}{*}{ Site } & \multirow[t]{2}{*}{ Ox.cl. } & \multicolumn{4}{|c|}{ IZZI-Thellier } & \multicolumn{4}{|l|}{ MSP } & \multicolumn{4}{|c|}{ pseudo-Thellier } & \multicolumn{4}{|c|}{ Microwave Thellier } \\
\hline & & PI & $\sigma$ & $\sigma / \mathrm{PI}$ & $\mathrm{n}(\mathrm{N})$ & Type & Average & Range & $\mathrm{n}(\mathrm{N})$ & PI & $\sigma$ & $\sigma / \mathrm{PI}$ & $\mathrm{n}(\mathrm{N})$ & PI & $\sigma$ & $\sigma / \mathrm{PI}$ & $\mathrm{n}(\mathrm{N})$ \\
\hline DB & I & $81.4^{*}$ & 17.1 & $21 \%$ & $2(7)$ & & & & & & & & $0(5)$ & & & & $0(1)$ \\
\hline EI1 & III-IV & 36.8 & 4.2 & $11 \%$ & $4(6)$ & & & & & 31.4 & 2.2 & $7 \%$ & $5(5)$ & & & & $0(1)$ \\
\hline EI2 & III-IV & 29.1 & 0.9 & $3 \%$ & $7(8)$ & DSC & 20.6 & $14.0-23.9$ & $8(12)$ & & & & $0(5)$ & 31.7 & & & $1(1)$ \\
\hline HL & I-II & & & & $0(7)$ & DB & 32.8 & $29.7-35.2$ & $8(12)$ & & & & $0(5)$ & & & & $0(1)$ \\
\hline HS & I & 40.8 & 1.0 & $2 \%$ & $3(8)$ & & & & & 37.5 & 0.6 & $2 \%$ & $3(5)$ & 32.7 & & & $1(1)$ \\
\hline KB & III-IV & 28.3 & 3.2 & $11 \%$ & $5(8)$ & & & & & $37.0^{*}$ & $\mathrm{n} / \mathrm{a}$ & $\mathrm{n} / \mathrm{a}$ & $1(5)$ & 25.6 & & & $1(2)$ \\
\hline MK & I-II & & & & $0(6)$ & & & & & $28.0^{*}$ & $\mathrm{n} / \mathrm{a}$ & $\mathrm{n} / \mathrm{a}$ & $1(5)$ & $10.1^{\#}$ & & & $1(1)$ \\
\hline $\mathrm{pH} 2$ & II-III & $52.4^{*}$ & 5.1 & $10 \%$ & $2(7)$ & & & & & 24.2 & 3.3 & $14 \%$ & $3(5)$ & $38.9^{\#}$ & & & 1 (1) \\
\hline PL & III & 33.0 & 3.3 & $10 \%$ & $6(7)$ & DB & 29.8 & $27.1-32.9$ & $9(10)$ & 34.9 & 0.5 & $1 \%$ & $5(5)$ & $20.4^{(\#)}$ & & & $1(1)$ \\
\hline SI & I-II & & & & $0(7)$ & DB & 36.0 & $34.1-37.6$ & $9(12)$ & & & & $0(5)$ & $25.2^{(\#)}$ & & & $1(1)$ \\
\hline TB & III-IV & 41.3 & 5.2 & $13 \%$ & $6(7)$ & DSC & 32.6 & $31.0-34.0$ & $12(12)$ & $40.9^{*}$ & 1.0 & $2 \%$ & 2 (5) & 43.0 & 7.0 & $16 \%$ & $2(2)$ \\
\hline VK & III & 45.8 & 2.5 & $5 \%$ & $3(7)$ & & & & & 35.9 & 0.3 & $1 \%$ & 2 (\%) & 32.8 & & & 1 (1) \\
\hline
\end{tabular}

are remarkably constant, as the parameters that check for directional stability $\left(\mathrm{MAD}_{\mathrm{anc}}\right.$ and $\alpha$ ) are generally much lower than the limits set by the selection criteria (15 and 15 for TTB and 6 and 15 for TTA, respectively). The $\mathrm{MAD}_{\mathrm{anc}}$ is $<7.5$ for all samples passing the criteria, except for the two DB samples; and $\alpha$ is $<7.5$ for all but three samples passing the selection criteria. Samples from the other sites (HL, MK, PH2 and SI) show sagging indicative of multidomain behaviour, samples from these sites are therefore often rejected. The obtained palaeointensities range from 20 to $45 \mu \mathrm{T}$ for most sites. Site $\mathrm{PH} 2$ has higher palaeointensities of $52.4 \pm 5.1 \mu \mathrm{T}$ (mean and one standard deviation) while site DB is even higher with $81.4 \pm 17.1 \mu \mathrm{T}$. The high value obtained for site $\mathrm{PH} 2$ may be explained by sagging: the palaeointensity value is obtained from the low-temperature (steep) part of the plot is thus probably on the high side. Site DB, on the other hand, yields straight Arai plots, but the two samples that pass the selection criteria differ: 69.2 versus $93.5 \mu \mathrm{T}$. Seven sites (EI1, EI2, HS, KB, PL, TB, and $\mathrm{VK}$ ) yield at least three successful samples, their site averages are therefore considered acceptable (Table 2).
Of the eight sites that do not show an overprint in their Zijderveld diagrams, five pass the ARM test (insets in Fig. 5; also see Appendix E). Sites EI2, SI and TB pass the test at $250^{\circ} \mathrm{C}$, and sites HL and PL at $200^{\circ} \mathrm{C}$. MSP data are provided in Appendix F. Sites PL, SI and TB yield MSP-DB plots with high $r^{2}$ values and few outliers, whereas sites EI2 and HL show more scatter. Palaeointensity values vary from $28 \mu \mathrm{T}$ (site EI2) to $36.0 \mu \mathrm{T}$ (site SI). Only sites EI2 and TB passed the selection criteria for the MSP-DSC protocol. Site TB's MSP-DB and MSP-DSC results are indistinguishable with respectively 32.8 [29.7-35.5] $\mu \mathrm{T}$ and $32.6[31.0-34.0] \mu \mathrm{T}$, adding to the credibility of the obtained palaeointensity value. For site EI2, on the other hand, the DSC protocol $(20.6[14.0-23.9] \mu \mathrm{T})$ yields a palaeointensity that is $7.1 \mu \mathrm{T}$ lower than that of the DB protocol $(27.7$ [16.7-32.6] $\mu \mathrm{T})$. The other three processed sites either fail the alteration criterion $\varepsilon_{\text {alt }}<3 \%$ (sites HL and SI) or the criterion that the linear regression should intersect with the $y$ axis within error of $(0,-1)$ (site PL). For these three sites, therefore, the MSP-DB protocol outcome is preferred (Table 2).

Pseudo-Thellier palaeointensities are determined for eight out of 
twelve sites (Fig. 5 and Appendix G). The success rate for individual specimens is $38 \%$ ( 22 out of 58 specimens). The remaining $62 \%$ either show non-linear ARM-versus-NRM demagnetisation diagrams (sites DB, $\mathrm{HL}$ and some specimens from VK) or fail the $\mathrm{B}_{1 / 2 \mathrm{ARM}}$ criterion (sites EI2 and SI, and some specimens from sites $\mathrm{KB}, \mathrm{MK}, \mathrm{PH} 2$ and TB). The obtained palaeointensities vary between $24 \mu \mathrm{T}$ (site PH2) and $41 \mu \mathrm{T}$ (site TB). Sites HS and PL yield the most linear plots and most consistent palaeointensities (standard deviations of 0.6 and $0.5 \mu \mathrm{T}$, respectively). Only four out of our twelve sites (EI1, HS, PH2, and PL) yielded at least three interpretable samples per site, their site averages are therefore accepted.

Microwave results for one or two specimens per site are shown in Fig. 5 and Appendix H. Palaeointensities are derived for 10 out of 14 measurements, a success rate of $71 \%$. The obtained Arai plots are generally very linear, with the exception of sites MK and SI and sample VK22b, which show sagging. Site PL's two-slope behaviour (Fig. 5) is probably due to its overprint in the first few microwave steps, as its Thellier-Thellier Arai plots are mostly linear. The obtained palaeointensities vary from $\sim 10 \mu \mathrm{T}$ (site MK, sagging) and $\sim 48 \mu \mathrm{T}$ (sample TB14b). Some samples (most notably site DB) show a significant overprint in the $\mathrm{z}$ direction (cylinder axis), suggesting partial remagnetisation caused by drilling the smaller 5-mm diameter samples from the original 1-in. diameter samples. The linear fit with the highest quality factor q (Coe et al., 1978) was preferred (automatic ThellierTool, cf. Leonhardt et al., 2004), although for some sites a second, manual regression is calculated excluding the overprint. Differences between the obtained palaeointensities with these two approaches are smaller than $2 \mu \mathrm{T}$.

\section{Discussion}

\subsection{Palaeomagnetic directions}

Our inclinations agree well with those reported by Böhnel et al. (1982) and Schnepp (1996); our declinations, however, often differ slightly (Fig. 6, top and middle panels, Appendix B). Sites DB, HL, MK, PH2 and TB are indistinguishable from Böhnel et al. (1982) and Schnepp (1996)'s results. Most of the deviation in the other sites may be attributed to the orientation differences between a magnetic compass and a sun compass: in none of the studies sun compass readings could be obtained for all sites. Indeed, for site KB, most of the $11.1^{\circ}$ difference between our declination and Böhnel et al. (1982) and Schnepp (1996)'s could be explained by the average sun compass correction of nearly $8^{\circ}$ for that site. Similarly, the $11.5^{\circ}$ difference observed for site MK may be due to our lack of sun compass readings. In this matter it is encouraging that sites DB and HL which have large sun compass corrections in our data set, overlap with those of Böhnel et al. (1982) and Schnepp (1996). Site SI showed large cracks during our sampling trip, so in this case it is possible that our sampling location was not entirely in situ. For sites EI1-2 and PL with large deviations of $\sim 20^{\circ}$ a different explanation is needed, as the sun compass corrections are too small to account for the observed declination differences. One possibility is the different sampling strategies that were employed: Böhnel et al. (1982) and Schnepp (1996)'s samples were spread over distances of several tens or hundreds of metres, whereas our samples were generally drilled in clusters and/ or were only taken several metres apart. So-called local anomalies due to terrain effects (e.g. Baag et al., 1995; Valet and Soler, 1999) in our data would therefore not be averaged out as good as in Böhnel et al. (1982) and Schnepp (1996)'s data. However, as Böhnel et al. (1982) and Schnepp (1996)'s palaeodirections generally showed low scatter ( $\alpha_{95}$ usually less than $4^{\circ}$ ), it appears unlikely that these large deviations would be due to the sampling method. The most plausible explanation therefore seems that, while we did sample the same eruption centres, we did not always sample exactly the same flows as Böhnel et al. (1982) and Schnepp (1996). Particularly in the case of EI1-2 this is plausible, as Böhnel et al. (1982) and Schnepp (1996) sampled scorias on the southwestern part of the Eiterköpfe, whereas we sampled massive lava flows a few hundred metres to the north.

\subsection{Palaeointensities}

The East Eifel volcanic field generally yields good and consistent palaeointensities. For ten sites the results of at least one palaeointensity method passes the selection criteria as outlined in the methods section (Fig. 6). Success rates of individual methods are appreciable. IZZIThellier yields $45 \%$ with specimens coming from nine sites; seven sites have at least three specimens passing the selection criteria and therefore yield acceptable estimates of the paleofield. Sites EI1, EI2, PL, and $\mathrm{TB}$, perform particularly well with most specimens attempted giving interpretable Arai diagrams. Sites DB, and PH2 have only two successful specimens and therefore do not produce an IZZI-Thellier site average. Sites HL, MK, and SI, have none and are disappointing. In the MSP approach, the ARM test passes for five sites. Two sites (EI2 and TB) fulfil all MSP-DSC criteria, one site (PL) has a slightly too large deviation from the theoretically predicted $(0,-1) \mathrm{y}$-axis intersection while two others (HL and SI) alter too much. In these latter three sites the MSP-DB number is selected, suggesting an upper bound to the palaeointensity value. In the pseudo-Thellier approach $38 \%$ of the specimens, from eight sites, pass. Sites DB, EI2, HL, and SI fail for all specimens tried. However, of the eight passing sites, four (KB, MK, TB, and VK) have only 1 or 2 successful specimens which we deem low for a meaningful result. So, a pseudo-Thellier PI value can be allocated to four sites: EI1, HS, PH2, and PL. The microwave method yields successful determinations for 10 out of 14 specimens (71\%). The number of specimens processed per site is unfortunately rather low: often just one per site. So, where applicable the microwave PI results are interpreted as supportive for the other approaches. Nine sites yield an interpretable Arai diagram; site TB has two successful specimens. The success rate decreases to $57 \%$ when two specimens with evident sagging (MK, PH2) are excluded from further interpretation. Two more specimens (PL, SI) are retained because their sagging is considered subtle.

IZZI-Thellier palaeointensity site means vary from $\sim 28$ to $\sim 81 \mu \mathrm{T}$ with four out of nine values straddling 40-45 $\mu \mathrm{T}$ (Fig. 6, lowermost panel, Table 2). MSP values range $\sim 21$ to $\sim 36 \mu \mathrm{T}$ and microwave palaeointensities from $\sim 20$ to $\sim 44 \mu \mathrm{T}$ (Fig. 6, Table 2). MSP data tend to be slightly lower than IZZI-Thellier data. The pseudo-Thellier method generally agrees with results from the other methods. The calibration formula (de Groot et al., 2015), which is based on data from Hawaii (de Groot et al., 2013) and the Canary Islands (de Groot et al., 2015), therefore seems to be applicable to the Eifel volcanism as well.

\subsection{Comparing paleointensity methods}

Sites DB and MK do not yield any estimates of the paleofield's intensity that pass our quality criteria as outlined before. Site DB yields some IZZI and microwave data; however, both are of low quality and their outcome differs rather substantially, therefore this site is not considered further. Sites HL, and PH2 only deliver one intensity that passes the pre-defined selection criteria (one MSP-DB and one pseudoThellier result, respectively). The remaining sites work for two, three, or even all four, approaches. Two approaches are technically successful in four sites: EI1, KB, SI, and VK. Sites EI1 and PH2 (albeit that the IZZI data are of somewhat lower quality) deliver results for IZZI and pseudoThellier (respectively 36.8 and $31.4 \mu \mathrm{T}$; and 52.4 and $24.2 \mu \mathrm{T}$ ). For both these sites the pseudo-Thellier results are (considerably) lower than the pseudo-Thellier results. For $\mathrm{PH} 2$ the lower temperature steps are interpreted, if subtle sagging occurs during the experiment, the lower temperatures may lead to an overestimate of the paleofield. This can explain the discrepancy between the IZZI-Thellier and pseudo-Thellier results, and would imply that the pseudo-Thellier results is closer to the actual paleofield. For site EI1 this explanation does not apply, as the entire temperature spectrum is used to obtain the IZZI-Thellier 

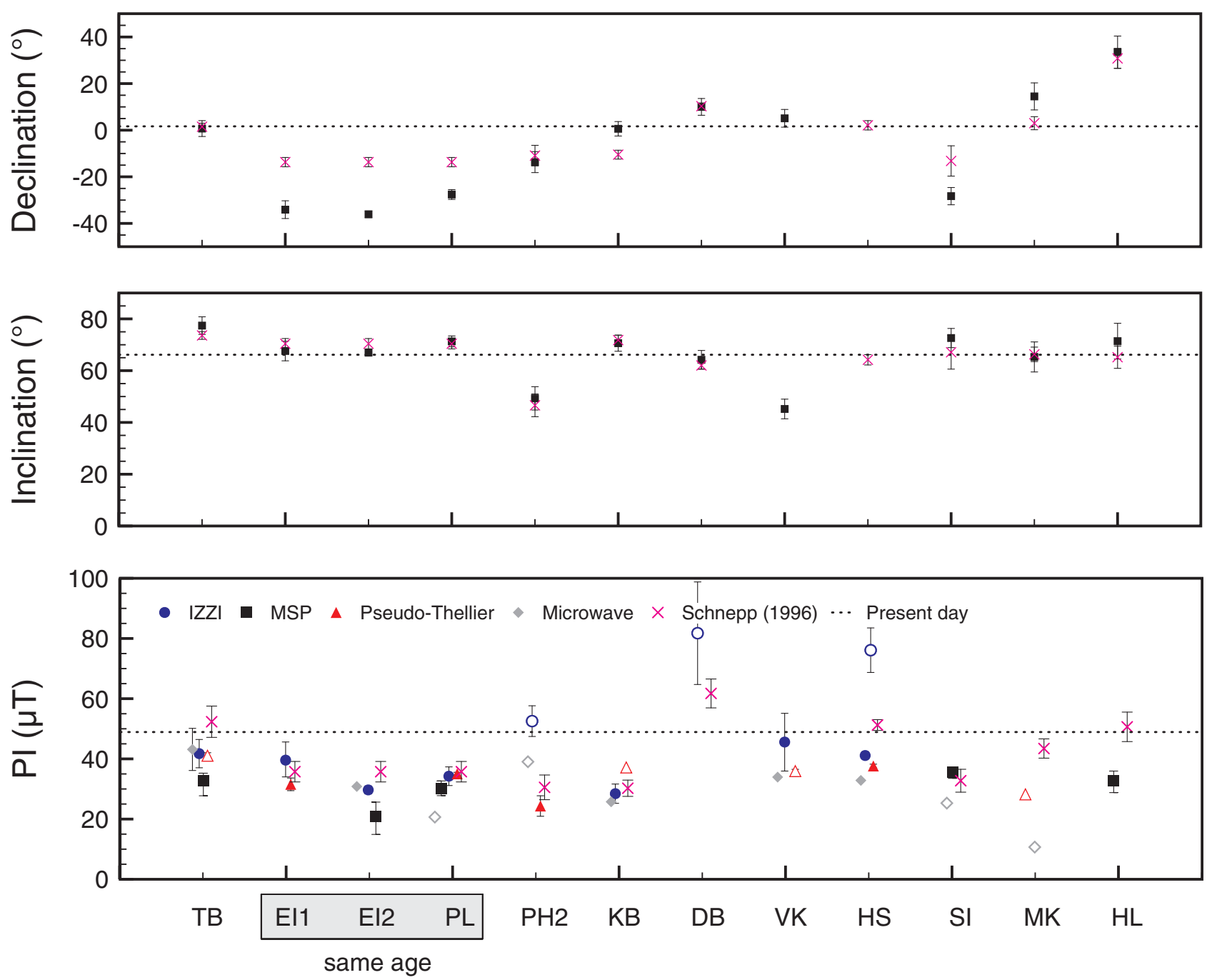

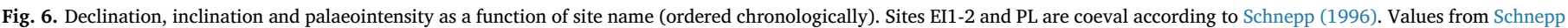

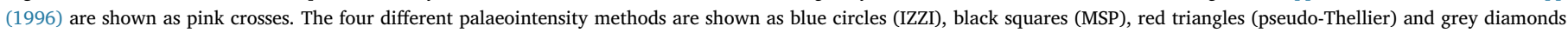

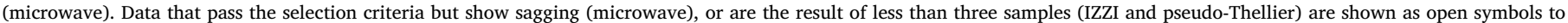

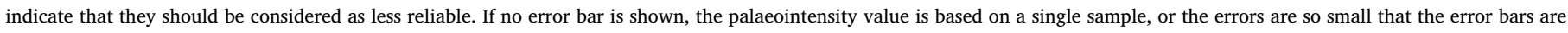

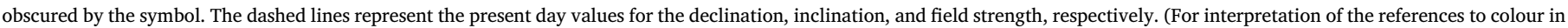
this figure legend, the reader is referred to the web version of this article.)

paleointensity, and there are no signs of sagging.

Site KB yields IZZI $(28.3 \mu \mathrm{T})$ and microwave data $(25.6 \mu \mathrm{T})$ that meet the selection criteria, and their results agree within error. Three approaches are technically successful in three sites: EI2, HS, and TB. Site EI2 works for IZZI-Thellier $(29.1 \mu \mathrm{T})$, MSP-DSC $(20.6 \mu \mathrm{T})$, and microwave $(31.7 \mu \mathrm{T})$; site TB gives respectively $41.3 \mu \mathrm{T}, 32.6 \mu \mathrm{T}$, and $43.0 \mu \mathrm{T}$. It is noteworthy that the IZZI-Thellier and pseudo-Thellier numbers are indistinguishable within error, while the MSP results are lower. This is in line with previous observations (e.g. de Groot et al., 2013; de Groot et al., 2015; Monster et al., 2015a,b), but this observation lacks a satisfying explanation. Site HS delivers IZZI-Thellier, pseudo-Thellier and microwave results (respectively 40.8, 37.5, and $32.7 \mu \mathrm{T}$ ). Site PL delivers results for all four methods. The three absolute palaeointensity methods (IZZI-Thellier, MSP, and Microwave Thellier) deliver consistent results as documented by site PL in Fig. 5 and Table 2. The IZZI average is $33.0 \mu \mathrm{T}$ and the MSP-DB result $29.8 \mu \mathrm{T}$ (MSP-DSC would be $29.2 \mu \mathrm{T}$ ); the microwave result is rather low $(22.1 \mu \mathrm{T})$. The pseudo-Thellier is $34.9 \mu \mathrm{T}$. The IZZI, MSP, and pseudoThellier overlap within uncertainty envelopes. The consistency between the different methods adds considerably to the credibility of the obtained values (see also de Groot et al., 2013; Paterson et al., 2014;
Monster et al., 2015a).

Ten out of twelve sites deliver a palaeointensity result that we consider meaningful. Outliers are often IZZI-Thellier or microwaveThellier results that pass our selection criteria but are considered not reliable because of sagging (e.g. site PH2), and/or MSP results that are generally on the low side of the obtained paleointensities per site. The younger units tend to be more oxidised with oxidation classes III-IV, while the older units usually are class I or I-II (Table 1). Curie point temperatures are often $\sim 540^{\circ} \mathrm{C}$ indicative of low-Ti titanomagnetite. Alteration temperatures are often lower than Curie temperatures so that determination of the latter may be slightly biased. The less oxidised flows occasionally have a lower $\mathrm{T}_{\mathrm{C}}$ but there is no evident trend. Although sites DB and MK do not show major alteration in the preliminary experiments and have low oxidation states, they yield very few and/or inconsistent paleointensity results. Possible explanations could be (1) an unsuitable chemical composition of the grains leading to subtle alteration during the experiments that goes undetected by the preliminary rock-magnetic analyses; (2) cumulative alteration induced by the many treatment steps in all paleointensity methods; or (3) a NRM domain state that is cured or evolved over time (e.g. de Groot et al., 2014) hampering a reliable relation between the domain states 
imparted during the paleointensity experiments. More oxidised sites (class III and III-IV) appear to work in 2, 3, or even all 4 approaches. This is in line with other paleointensity studies. This counterintuitive observation might be explained by the pinning of domain walls on sharp transitions within the grains (de Groot et al., 2014); i.e. we hypothesize that the oxidation zones/lamellae may have a stabilizing effect on the domain configuration of the magnetic remanence carrying grains and the reproducibility of the magnetic domain state during the paleointensity experiments.

\subsection{The veracity of the multi-method paleointensity approach}

Since 2013 a number of studies have adopted the multi-method paleointensity approach and subjected samples to at least three different paleointensity techniques (de Groot et al., 2013, 2015, 2016; Ertepinar et al., 2016; Monster et al., 2015a,b). If paleointensity techniques based on different systems of exciting the magnetic spin system of the remanence carrying grains (thermal, microwave, or alternating fields) independently produce the same result, the credibility of this result is greatly enhanced. If the methods disagree, it is the task of the interpreter to give meaning to the obtained results. A full review of the multitude of effects that can hamper paleointensity experiments is beyond the scope of this research, but in general terms we observe that multi-specimen results tend to be slightly lower than IZZI-Thellier results; and pseudo-Thellier and microwave results are often in between the MSP and IZZI-Thellier results. Furthermore, it is remarkable that for sites that fail in thermal paleointensity experiments the pseudo-Thellier and Microwave Thellier experiments often produce the same, and meaningful results. This implies that the potential of choosing a paleointensity technique that avoids thermal steps completely (pseudoThellier), or largely (Microwave Thellier) cannot be underestimated for samples that suffer from thermal alteration during IZZI-Thellier, or MSP experiments.

\subsection{Comparison with existing palaeointensity data}

All in all, the new palaeointensities compare well to those determined by Schnepp (1996) as shown in Fig. 6. Sites EI1, PL, KB, and SI are indistinguishable, albeit that our determination for HL comes with a fairly large uncertainty. Our results for sites TB and HS are $\sim 10 \mu \mathrm{T}$ lower than Schnepp's (1996) determination. The quality of the present palaeointensity estimates for sites DB and MK fail our selection criteria while Schnepp (1996) does not report a palaeointensity for site VK. Site PH2 delivers a rather high IZZI-Thellier result while the pseudo-Thellier technique yields the same answer as Schnepp (1996). It could be that our higher IZZI data are influenced by sagging. Sites EI1, EI2, and PL are considered coeval. Paleointensities indeed overlap over the various approaches adopted here; Schnepp's (1996) Coe-Thellier data are a few $\mu \mathrm{T}$ higher but within uncertainty envelopes (Fig. 6).

Most palaeointensity values range $30-35 \mu \mathrm{T}$, slightly lower than the average intensity for the Brunhes chron, converted from the VADM (virtual axial dipole moment) in Ziegler et al. (2011). Directional changes are compatible with palaeosecular variation, so unlike in the West Eifel, no excursion-related palaeointensity lows are anticipated. This concurs perfectly with observations in both Schnepp $(1995,1996)$ and the present study. Most radiometric ages come with a rather large uncertainty which pleads for a re-dating effort, similar to that performed by Singer et al. (2008) for the West Eifel volcanic field. By redating with improved Ar-Ar methodology they could tie paleointensity lows with associated excursional paleomagnetic directions, taken from Schnepp and Hradetsky (1994), to geomagnetic excursions determined elsewhere which testifies their reality and global nature. The palaeointensities obtained here for the older sites (HS to HL) are in agreement with the average palaeointensity expected for the period 0.3-300 Ma (Selkin and Tauxe, 2000; VADMs converted to field intensity), whereas the sites with ages $<0.3 \mathrm{Ma}$ (TB to VK) seem rather low. These data agree very well with the average over the period 0.3-300 Ma, perhaps suggesting an earlier or more gradual decrease of the average VADM between 200 and $300 \mathrm{ka}$. It should be kept in mind, however, that sites TB to DB are clustered together in age and the uncertainty intervals of their ages overlap. It is therefore possible that these flows were erupted in a relatively short period of lower than average field, also keeping in mind that sites EI1, EI2, and PL are considered coeval.

\section{Conclusions}

The multi-method palaeointensity approach used in this study yields reliable palaeointensity values for ten out of twelve sites. Within-site results are generally consistent and usually within error of the results reported by Böhnel et al. (1982) and Schnepp (1996). No excursional directions with associated palaeointensity lows are found; palaeointensity values typically are 30-35 $\mu \mathrm{T}$, slightly below the Brunhes Chron average and compatible with the $0.3-300 \mathrm{Ma}$ average. Considering the high success rates and the often linear Arai plots, the Eifel appears to be an attractive location for future palaeointensity investigations. Full-vector records could be better constrained by new, more precise radio-isotope ages. With more precise ages and (re-)sampling all available locations a regional full-vector PSV curve for NW Europe for 200-700 ka could be established.

\section{Acknowledgements}

This research was funded by a grant from the Earth and Life Sciences Division (ALW) of the Netherlands Organisation for Scientific Research (NWO). MWLM would like to thank Elisabeth Schnepp for sharing her notes on the original sampling locations, and Cor Langereis and Maryam Honarmand for their help on a preliminary field trip to locate the original sites. She would also like to thank the overseers of the Tönchesberg, Plaidter Hummerich and Plaidt quarries for allowing sampling in their quarries and in particular Herr Winter of the Zentraldeponie Eiterköpfe for granting us access to locked parts of the quarry. We thank Yongjae Yu for his thorough review of this manuscript.

\section{Appendix A. Supplementary data}

Supplementary data associated with this article can be found, in the online version, at http://dx.doi.org/10.1016/j.pepi.2017.11.009.

\section{References}

Baag, C., Helsley, C.E., Xu, S.Z., Lienert, B.R., 1995. Deflection of paleomagnetic directions due to magnetization of underlying terrain. J. Geophys. Res. 100, 10013-10027.

Böhnel, H.N., Kohnen, H., Negendank, J., Schmincke, H.-U., 1982. Paleomagnetism of quaternary volcanics of the East-Eifel, Germany. J. Geophys. 51, 29-37.

Chadima, M., Hrouda, F., 2006. Remasoft 3.0 - a user-friendly paleomagnetic data browser and analyzer. Travaux Géophysiques XXVII, 20-21.

Coe, R.S., 1967. Paleointensities of the earth's magnetic field determined from tertiary and quaternary rocks. J. Geophys. Res. 72, 3247-3262. http://dx.doi.org/10.1029/ JZ072i012p03247.

Coe, R.S., Gromme, S., Mankinen, E.A., 1978. Geomagnetic paleointensities from radiocarbon-dated lava flows on Hawaii and question of Pacific dipole low. J. Geophys. Res. 83, 1740-1756.

Day, R., Fuller, M., Schmidt, V.A., 1977. Hysteresis properties of titanomagnetites - grainsize and compositional dependence. Phys. Earth Planet. Inter. 13, 260-267. http:// dx.doi.org/10.1016/0031-9201(77)90108-X.

de Groot, L.V., Béguin, A., Kosters, M.E., van Rijsingen, E.M., Struijk, E.L.M., Biggin, A.J. Hurst, E.A., Langereis, C.G., Dekkers, M.J., 2015. High paleointensities for the Canary Islands constrain the Levant geomagnetic high. Earth Planet. Sci. Lett. 419, 154-167. http://dx.doi.org/10.1016/j.epsl.2015.03.020.

de Groot, L.V., Biggin, A.J., Dekkers, M.J., Langereis, C.G., Herrero-Bervera, E., 2013. Rapid regional perturbations to the recent global geomagnetic decay revealed by a new Hawaiian record. Nat. Commun. 4, 3727. http://dx.doi.org/10.1038/ ncomms3727.

de Groot, L.V., Dekkers, M.J., Mullender, T.A.T., 2012. Exploring the potential of 
acquisition curves of the anhysteretic remanent magnetization as a tool to detect subtle magnetic alteration induced by heating. Phys. Earth Planet. Inter. 194, 71-84. http://dx.doi.org/10.1016/j.pepi.2012.01.006.

de Groot, L.V., Fabian, K., Bakelaar, I.A., Dekkers, M.J., 2014. Magnetic force microscopy reveals meta-stable magnetic domain states that prevent reliable absolute palaeointensity experiments. Nat. Commun. 5, ncomms5548. http://dx.doi.org/10. 1038/ncomms5548.

de Groot, L.V., Pimentel, A., Di Chiara, A., 2016. The multimethod palaeointensity approach applied to volcanics from Terceira: full-vector geomagnetic data for the past 50 kyr. Geophys. J. Int. 206, 590-604. http://dx.doi.org/10.1093/gji/ggw095.

Dekkers, M.J., Böhnel, H.N., 2006. Reliable absolute palaeointensities independent of magnetic domain state. Earth Planet. Sci. Lett. 248, 508-517. http://dx.doi.org/10. 1016/j.epsl.2006.05.040.

Dunlop, D.J., 2002. Theory and application of the Day plot (Mrs/ Ms versus Hcr/ Hc) 1. Theoretical curves and tests using titanomagnetite data. J. Geophys. Res. 107, 2056. http://dx.doi.org/10.1029/2001JB000486.

Ertepinar, P., Langereis, C.G., Biggin, A.J., de Groot, L.V., Kulakoğlu, F., Omura, S., Süel, A., 2016. Full vector archaeomagnetic records from Anatolia between 2400 and 1350 BCE: implications for geomagnetic field models and the dating of fires in antiquity. Earth Planet. Sci. Lett. 434, 171-186. http://dx.doi.org/10.1016/j.epsl.2015.11.015.

Fabian, K., Leonhardt, R., 2010. Multiple-specimen absolute paleointensity determination: an optimal protocol including pTRM normalization, domain-state correction, and alteration test. Earth Planet. Sci. Lett. 297, 84-94. http://dx.doi.org/10.1016/j. epsl.2010.06.006.

Fuhrmann, U., Lippolt, H.J., 1985. Excess argon and dating of Quaternary Eifel volcanism: I. The Schellkopf alkali phonolite/East Eifel. Neues Jb. Geol. Paläont. Mh. H8, 484-497.

Fuhrmann, U., Lippolt, H.J., 1986. Excess argon and dating of Quaternary Eifel volcanism: II. Phonolitic and foiditic rocks near Rieden, East Eifel/FRG. Neues Jahrb. Geol. Paläontol. Abh. 172, 1-19.

Hill, M.J., Shaw, J., 1999. Palaeointensity results for historic lavas from Mt Etna using microwave demagnetization/remagnetization in a modified Thellier-type experiment. Geophys. J. Int. 139, 583-590.

Knudsen, M.F., Riisager, P., Donadini, F., Snowball, I., Muscheler, R., Korhonen, K., Pesonen, L.J., 2008. Variations in the geomagnetic dipole moment during the Holocene and the past 50 kyr. Earth Planet. Sci. Lett. 272, 319-329. http://dx.doi. org/10.1016/j.epsl.2008.04.048.

Leonhardt, R., Heunemann, C., Krása, D., 2004. Analyzing absolute paleointensity determinations: acceptance criteria and the software ThellierTool 4.0. Geochem. Geophys. Geosyst. 5, Q12016. http://dx.doi.org/10.1029/2004GC000807.

Meyer, W., 1986. Geologie der Eifel. Schweizerbart 1-615.

Monster, M.W.L., de Groot, L.V., Biggin, A.J., Dekkers, M.J., 2015a. The performance of various palaeointensity techniques as a function of rock magnetic behaviour - a case study for La Palma. Phys. Earth Planet. Inter. 242, 36-49. http://dx.doi.org/10.1016/ j.pepi.2015.03.004.

Monster, M.W.L., de Groot, L.V., Dekkers, M.J., 2015b. MSP-tool: a VBA-based software tool for the analysis of multispecimen paleointensity data. Front. Earth Sci. 3, 86. http://dx.doi.org/10.3389/feart.2015.00086.

Mullender, T.A.T., Frederichs, T., Hilgenfeldt, C., de Groot, L.V., Fabian, K., Dekkers, M.J., 2016. Automated paleomagnetic and rock magnetic data acquisition with an inline horizontal " $2 \mathrm{G}$ ” system. Geochem. Geophys. Geosyst. 17, 3546-3559. http://dx. doi.org/10.1002/2016GC006436.

Paterson, G.A., Tauxe, L., Biggin, A.J., Shaar, R., Jonestrask, L.C., 2014. On improving the selection of Thellier-type paleointensity data. Geochem. Geophys. Geosyst. 15 ,
1180-1192. http://dx.doi.org/10.1002/2013GC005135.

Petrovský, E., Kapicka, A., 2006. On determination of the Curie point from thermomagnetic curves. J. Geophys. Res. 111, B12S27. http://dx.doi.org/10.1029/ 2006JB004507.

Riisager, P., Riisager, J., 2001. Detecting multidomain magnetic grains in Thellier palaeointensity experiments. Phys. Earth Planet. Inter. 125, 111-117. http://dx.doi. org/10.1016/S0031-9201(01)00236-9.

Ritter, J.R.R., Jordan, M., Christensen, U.R., Achauer, U., 2001. A mantle plume below the Eifel volcanic celds, Germany. Earth Planet. Sci. Lett. 186, 7-14.

Schmincke, H.U., 2007. The Quaternary volcanic fields of the East and West Eifel (Germany). In: Ritter, J.R.R., Christensen, U.R. (Eds.), Mantle Plumes - A Multidisciplinary Approach. Springer, pp. 241-322.

Schmincke, H.U., Mertes, H., 1979. Pliocene and quaternary volcanic phases in the Eifel volcanic fields. Naturwissenschaften 66, 614-615. http://dx.doi.org/10.1007/ BF00405123.

Schnepp, E., 1994. Determination of geomagnetic palaeointensities from the Quaternary West Eifel volcanic field, Germany. Geophys. J. Int. 116, 688-714.

Schnepp, E., 1995. Palaeointensity study of Quaternary East Eifel phonolitic rocks (Germany). Geophys. J. Int. 121, 627-633.

Schnepp, E., 1996. Geomagnetic paleointensities derived from volcanic rocks of the Quaternary East Eifel volcanic field, Germany. Phys. Earth Planet. Inter. 94, 23-41. http://dx.doi.org/10.1016/0031-9201(95)03096-4.

Schnepp, E., Hradetsky, H., 1994. Combined plaeointensity and age spectrum data from volcanic rocks of the West Eifel field (Germany): evidence for an early Brunhes geomagnetic excursion. J. Geophys. Res. 99, 9061-9076.

Selkin, P.A., Tauxe, L., 2000. Long-term variations in palaeointensity. Philos. Trans. Math. Phys. Eng. Sci. 358, 1065-1088.

Singer, B.S., Hoffman, K.A., Schnepp, E., Guillou, H., 2008. Multiple Brunhes Chron excursions in the West Eifel (Germany) volcanics: support for long-held mantle control over the on-axial dipole field. Phys. Earth Planet. Inter. 169, 28-40.

Tauxe, L., Pick, T., Kok, Y.S., 1995. Relative paleointensity in sediments - a pseudothellier approach. Geophys. Res. Lett. 22, 2885-2888.

Tauxe, L., Staudigel, H., 2004. Strength of the geomagnetic field in the Cretaceous Normal Superchron: new data from submarine basaltic glass of the Troodos Ophiolite. Geochem. Geophys. Geosyst. 5.

Thellier, E., Thellier, O., 1959. Sur l'intensité du champ magnétique terrestre dans le passé historique et géologique. Ann. Geophys. 15, 285-378.

Valet, J.P., Soler, V., 1999. Magnetic anomalies of lava fields in the Canary islands. Possible consequences for paleomagnetic records. Phys. Earth Planet. Inter. 115, 109-118.

van den Bogaard, C., van den Bogaard, P., Schmincke, H.-U., 1989. Quartärgeologisch tephrostratigraphische Neuaufnahme und Interpretation des Pleistozänprofils Kärlich. Eiszeitalter und Gegenwart 39, 62-86.

Watkins, N.D., Haggerty, S.E., 1968. Oxidation and magnetic polarity in single Icelandic lavas and dikes. Geophys. J. Int. 15, 305-315. http://dx.doi.org/10.1111/j.1365246X.1968.tb00187.x.

Yu, Y.J., Tauxe, L., Genevey, A., 2004. Toward an optimal geomagnetic field intensity determination technique. Geochem. Geophys. Geosyst. 5, Q02H07. http://dx.doi. org/10.1029/2003GC000630.

Ziegler, L.B., Constable, C.G., Johnson, C.L., Tauxe, L., 2011. PADM2M: a penalized maximum likelihood model of the 0-2 Ma palaeomagnetic axial dipole moment. Geophys. J. Int. 184, 1069-1089. http://dx.doi.org/10.1111/j.1365-246X.2010. 04905.x. 